\title{
The Dilemma and Breakthrough of the Solution of Medical Dispute
}

\author{
Zhongshan $\mathrm{Jin}^{1, \mathrm{a}}$ and Chen $\mathrm{Wei}^{2, \mathrm{~b}^{*}}$ \\ ${ }^{1}$ School of public health and management, Hubei University of Medicine, shiyan, China \\ ${ }^{2}$ School of humanity, Hubei University of Medicine, shiyan, China \\ a32787455@qq.com, b461370419@qq.com
}

*The corresponding author

\section{Keywords: Medical dispute; Civil Law; Criminal Law; Medical trouble}

\begin{abstract}
As we know, if the medical dispute mediation is not good, it will lead some vicious social events, which always violate the Criminal Law, and consequentially bring about very bad social influence. Even if the medical dispute mediation is good, it always involve Civil Law, and will absolutely cause civil compensation. This paper firstly presents the cause and class of the medical dispute based on principle of law and society, then gives the current legal solution of medical dispute and analysis why the usual legal solutions and society requirement do not well implement. Finally, the suggestions of how to break the dilemma of solution of medical dispute through legal and social development level are presented.
\end{abstract}

\section{Introduction}

Medical dispute is a hot issue of the society. As we know, if the medical dispute is not handled properly, it will evolve to the criminal incidents like hurting the doctor and medical incidents. Thus, in order to safeguard the security of the society, many provinces and cities in our country have tried to establish the medical dispute mediation system to resolve medical disputes for the medical disputes increase as well as the medical incidents occurred frequently grim reality. Fortunately, according to preliminary statistics, in the year of 2015, the number of National People's Mediation dispute is 71,000 , the mediation success rate is $85 \%$, and while the total number of medical treatment cases is increased, the number of medical disputes is continue declined [1]. But we have to face the following reality: the absolute number of medical treatment is still large, and the serious injure to doctor and medical incidents still have too much bad social influence, and we are not doing enough to solve the medical dispute. How to do our best to eliminate medical disputes? This paper will focus on the dilemma and breakthrough of the solution of medical dispute.

\section{The Cause and Class of the Medical Dispute}

Although, there is no medical institution and patient wants to have medical disputes, however, in many cases, the occurrence of medical disputes is inevitable in the accident. We can sum up the causes of medical disputes in the following three kinds:

(i) The most common one is, the dispute is caused by the medical behavior fault and negligence. Medical negligence is the fault of medical staff in the process of diagnosis and nursing. Medical fault is the fault of medical staff in medical activities, such as medical treatment and nursing. These faults or negligence usually lead to patient dissatisfaction or cause harm to the patient, and then cause the disputes. When this medical dispute happened, one may address the medical and health administrative departments to carry out the identification of medical accident based on the Regulations on Treatment of Medical Malpractice [2].

(ii) The second one is, although patients with physical damage do exist, doctor (medical institution) does not have any fault and negligence, only the patients' dissatisfaction can also cause medical dispute. The usual reason for such a dispute is patients are always lack of medical knowledge, and cannot understand the correct medical treatment, the natural outcome of the disease and accident in 
medical care. Even worse, the patient's unjustifiable blame may also cause medical dispute. However, when this kind medical dispute happened, patients can still be submitted to the forensic identification department, and the identification conclusions of patients' injure must be given by the authority, rather than the medical treatment of patients [2].

(iii) The final one refers to dispute of medical tort and medical breach. In this kind dispute, patients' privacy; informed consent and patient's consumption rights are always compromised in the course of medical treatment or outcome [3].

Briefly speaking, we can define medical disputes from the legal aspect: it is the dispute between providers and recipients of medical services on whether the medical acts and theirs consequences infringement and what the tort liability is. [4]

\section{The Usual Solution of Medical Dispute}

No matter what kind of medical disputes happened, in order to avoid the medical disputes evolved into criminal cases, one should make medical disputes properly resolved. The usual solution of medical disputes can be presented as: once the medical disputes happened, they, are belonged to property relations and personnel relations among the main equality body, are as the same as the civil disputes, and thus Civil law can be used to solve these disputes. According to the principle of "private law autonomy", usually, the state in principle does not need to interfere. Therefore, the parties can consult on medical disputes, and can also take civil mediation and administrative mediation. Theoretically, medical contract disputes can also be resolved by arbitration, but mediation to resolve medical disputes is not taken seriously currently. The actual situation is that the state intervention in medical civil disputes is very common, it is in the form of civil litigation (need the patients' sue). Additionally, patients can also apply for health administrative departments to solve the disputes [5].

Since medical disputes are applicable to the scope of civil law, the fault or negligence party should bear the corresponding liability. September 1, 2002 the State Council enacted the "Medical Malpractice Ordinance", which attributed the nature of civil liability of medical disputes to the tort liability of civil law. Who will bear the burden of proof? 2002, Supreme People's Court (SPC) did a judicial interpretation to the "Medical Malpractice Ordinance", it provides that if the infringement litigation is caused by medical actions, medical institution should bear the burden of proof of whether there are no causal relationship and no medical fault between the medical action and the outcome of the injury [6]. This judicial interpretation essentially takes the principle of fault presumption as the principle of civil liability for medical malpractice, and implements the burden of proof inversion in the medical malpractice case [7]. This is the usual legal way, which can help patients and medical institutions to solve theirs disputes.

\section{The Dilemma of the Usual Solution of Medical Dispute}

Theoretically, if one dealt with medical disputes based on the regulations of the above section, both sides (patients and medical institution) are satisfied with the ending of the dispute should be taken for granted. But, reality is not ideal, and usual solution of medical dispute is actually in dilemma.

First of all, the 7th chapter of "tort liability law", which is came into force in the July 1, 2010, specifies that it can be presumed the hospital has made fault once either of the following situations occurs: the hospital acts in violation of laws, administrative regulations, rules, the provisions of other relevant diagnostic and treatment norms, or, the hospital hides or refuses to provide medical records related to the dispute, forges, falsifies or destroys medical records [8]. Legally, this appears to be beneficial to the patient, the actual situation is that some of the burden of proof in doctor-patient dispute has been transferred to the patient side. Faced with the huge medical institution, how can individual patient burden proof? This situation seems can be solved by applying for health administrative departments to intervene, and this means need a series of administrative procedures and long evidence of investigation. But remember that, when the medical disputes happen, patients are often suffering from physical illness or even death, the longer patients wait to get evidence, the 
more likely patients are to have a physical and spirit injury. Finally, medical disputes evolve into a medical trouble with criminal responsibility.

Secondly, as we know that, the key core of the burden of proof is whether there is medical malpractice existed in medical disputes. But how to define medical malpractice is also not a trivial job based on jurisprudence. Medical malpractice is one kind of fault, and theoretically, the judgment of fault is controversial. There are two kinds of fault theories. One kind of fault theory is considering intention is a positive malice, negligence is a negative malicious [9]. If there is a causal relationship between behavior and outcome, while the perpetrator may foresee the results, thus perpetrator should foresee but not, then he (she) shall be liable for fault. The other one kind of fault theory emphasizes whether there is any fault in the objective behavior is essential in consideration of fault liability. Specifically, to determine whether the medical institutions have any fault depend on whether medical institutions take appropriate measures to avoid the occurrence of results, and this is the so-called special criteria of medical fault [10] . Obliviously, the latter kind of fault theory is more reasonable and thus it is widely accepted. But, what kind of independent institutions can identify the existence of such special criteria of medical fault? And how this identification is beneficial to the injured party? Who will supervise the identification process is illegal? If the patients do not recognize the results of the identification, and where is the appeal way of re-identification. These specific problems are not as simple as a legal clarification of a concept of fault theory.

Finally, laws and regulations usually guide the two sides of the parties how to dispose after the medical dispute have been happened. How to minimize the medical disputes before they are happened is also a helpful way of solve the medical dispute. This is what the current society is trying to promote, doctors must pay more attention to the doctor-patient relationship in the process of medical treatment. To doctors, the common measures are the requirements of improving their medical technology, pay more attention to Interrogation Language and manner, keep enough patience, smiling service etc [11]. To medical institutions, the common measures are the requirements of strictly medical examination system, severe medical accountability system, and scientific support of the doctor training system, perfect electronic and paper medical records etc. These measures can absolutely effectively prevent the occurrence of medical disputes, if and only if they can be truly effective implementation. Hospitals must pursue economic benefits in order to have sufficient resources to configure various hardware and software to carry out the scientific management. Obviously, if the hospital's economic is not good, how to ask improving the quality of medical service and the doctor's patience? These so-called effective ways to reduce medical disputes, they themselves have too strong market dependence, and thus the actual operability is difficult.

\section{The Suggestions of Breakthrough of the Solution of Medical Dispute}

As the above section shows that there are too many regulations and suggestions to deal with medical disputes, not only after the medical disputes indeed happen, but also before they happen. Although they can theoretically solve medical disputes, but sometimes they actually make the medical dispute into a certain degree of dilemma. Faced with the dilemma of solution of medical dispute, how to correct or break? We will give our following suggestions:

After the medical disputes happen, the most important work of solving medical dispute are laws and regulations should be in favor of vulnerable members, and accompanied by legal proceedings, the conciliation work for vulnerable members must be strengthened. The specific recommendations are:

(1) Like the 7th chapter of "tort liability law" shows that, some of the burden of proof in doctor-patient dispute has been transferred to the patient side. For such a disadvantage to vulnerable groups of the law must be supplemented accordingly complementary regulations. For example, when patients need to bear the burden of proof, by what level of the court designated appraisal institutions, selection principle of expert, paid (who paid?) or unpaid, how to define the level of dispute, the time span of disputes in different levels, the most important is how to comfort the injured (physical and 
psychological) patients during the identification etc. Whether these measures are implemented scientifically will determine in part whether the dispute will worsen.

(2) When the law is controversial in dealing with medical disputes, like the two kinds of fault theories, the SPC should specify in the written document which one should be adopted. However, the story is not ending any more, after the selected legal regulations by SPC law interpreting, one should keep a long time to popularize and supporting the amendment. As we know that legal disputes are often a long time, and the elimination of this controversy must be given a certain series of procedures to dispel doubts. Only in this way, one can really eliminate legal controversy from the theory to actual execution. And finally help to solve the medical disputes.

Before the medical disputes happen, the most important work of solving medical dispute is to mobilize all resources to reduce the possibility of medical disputes, this is not only a project for hospitals and doctors, but also a complex society project.

(1) In order to improve the doctors' medical technology, more attention to Interrogation Language and manner, keeping enough patience and smiling service etc, the doctors should be in a relatively comfortable working environment. Thus, the government and health management departments need to co-ordinate arrange for public hospitals or medical institutions, and the basic welfare salary (which should be at a high level) for doctors must be effectively guaranteed. Correspondingly, the entry threshold of doctor occupation must be improved. Fortunately, the current standard of training doctors and doctor professional qualification examination have the above-mentioned functions. We suggest that, under the premise of improving the doctors' salary, state should continue raising the threshold of occupation. College Entrance Examination is an important means to select the talents, and its guiding role is indubitable. The actual situation is that, in the college entrance examination both students with 300 points and 600 points can enter medical colleges, and then become doctors. Therefore, it is necessary to increase the enrollment scores of medical colleges in order to select more excellent students. High scores do not mean high-quality, but relatively speaking, in high-paying and comfortable working environment, the high-quality students with high scores will have a greater willingness to choose doctor career. It is easy to foresee that, the high-quality medical students will lead high-quality doctors, and then high-quality doctors will reduce the medical disputes.

(2) Only requirement of high-quality doctors is not enough to reduce the medical disputes, the requirement of high-quality patients and harmonious society are important too. As we know that, to improve the quality of the whole people and to construct a harmonious society is one of the goals of the socialist construction in China. High-quality patients means they can understand the correct medical treatment, the natural outcome of the disease and accident in medical care. The harmonious society means that, even the medical disputes happened, patients and doctors can tolerate each other. Mutual understanding and mutual tolerance between doctors and patients will absolutely reduce the medical disputes.

\section{Conclusions}

This paper begins with the cause and class of the medical dispute, then presents the usual legal solution of medical dispute. We analysis why the usual legal solutions and requirement of doctors and medical institutions are not good implementation from three aspects. Finally, we give our suggestions about how to break the solution of medical disputes.

\section{Acknowledgements}

The research work of this paper is supported partly by the 2015 Health Management and Health Care Development Research Center Open Fund (No. 2015ZD004) of Hubei University of Medicine and the 2013 graduate start-up found (No.2013QDJRW02) of Hubei University of Medicine. 


\section{References}

[1] Information on http://www.nhfpc.gov.cn/, one can also read the information on http://news.xinhuanet.com/yuqing/2016-02/25/c_128749708.htm.

[2] Yuan-Sheng Zhou, Medical dispute [M], China Procuratorate Press, China, 2002, p4.

[3] Ai ken-er, On the Third Party Mediation System of Medical Disputes in China [J], Western Law Review, 2015(1):30-46.

[4] Deng qing-hua, The Current Situation of Medical Disputes and the Way to Solve [J], 2015(11):1566-1568

[5] Wang zhi-gang, etc, Analysis the Current Situation of Medical Disputes [J]. ournal of Mathematical Medicine, 2015(1):57-59.

[6] Qu wen, etc, Influence of Mass Bias on Attribution and Responsibility Inference in Medical Disputes [J], Chinese Journal of Clinical Psychology, 2016, 24(2):213-217.

[7] Zhang wen-ying, Research on Designing Path of Medical Dispute Resolution System [J], Operation and management, 2016(16).

[8] Xi ya-ling, Problems in the Treatment Mechanism of Medical Disputes and Legal Countermeasures [J], Journal of Shenyang Official, 2015(2):39-40.

[9] Lei kai-liang: Countermeasure Analysis of Perfecting Medical Dispute Settlement Mechanism in China (MS, Shandong normal university, 2015).

[10] Lu ying, Weng li-wen, Legislative proposals on the treatment of medical disputes [J], China Health Law, 2016(1):75-78.

[11]Liu fang, The Application of Human Communication Skills in Medical Disputes [J], Company culture tri-monthly publication, 2016(4). 